\title{
Imagens preliminares do Atlas Linguístico-etnográfico do \\ Vale do Acará
}

Preliminary images of the Linguistic-Ethnographic Atlas of Acará Valley

Regis José da Cunha GUEDES*

Universidade Federal Rural da Amazônia (UFRA)

\begin{abstract}
RESUMO: Este estudo foi realizado a partir do corpus lexical do projeto Atlas Linguístico-etnográfico do Vale do Acará (ALEVA), com o objetivo de descrever e mapear a variação linguística da região do Vale do Acará, com atenção especial ao português em contato com as línguas Tembé e Japonesa, bem como à variedade quilombola. Nortearam este estudo os pressupostos teórico-metodológicos da Geossociolinguística (RAZKY, 1998) e da Dialetologia Pluridimensional e Relacional (RADTKE; THUN, 1998). Os dados foram coletados in loco a partir da aplicação do Questionário Semântico-Lexical (QSL) elaborado pelo Comitê Nacional do Atlas Linguístico do Brasil (ALiB, 2001). Foram entrevistados 6 colaboradores em cada um dos seis pontos de inquérito, perfazendo 36 entrevistados, estratificados por sexo (masculino e feminino) e idade ( 10 a 12, 18 a 40, e 50 a 75 anos, todos escolarizados no máximo até o ensino fundamental). Os resultados apontam para a existência de influências diaétnicas na variação lexical registrada a partir do mapeamento do item lexical libélula.
\end{abstract}

PALAVRAS-CHAVE: ALEVA. Geossociolinguística. Dialetologia Pluridimensional e Relacional

ABSTRACT: This study was carried out from the corpus of the LinguisticEthnographic Atlas of Acará Valley Project (ALEVA) aiming to describe and map the Vale do Rio Acará regional linguistic variation, specially the Portuguese one in contact with the Tembé and Japanese languages, as well Quilombola's. The theoretical and methodological assumptions of Geosociolinguistic (RAZKY, 1998) and Pluridimensional and Relational Dialectology (RADTKE; THUN, 1998) guided this study. Data were collected in loco by applying the Lexical Semantic Questionnaire (QSL) prepared by the National Committee of the Linguistic Atlas of Brazil (ALiB). Six employees were interviewed at each of the six survey points, making a total of 36 respondents, entratified by sex (male and female) and age (10-12, 18-40, and 50-75

* Professor Adjunto na Universidade Federal Rural da Amazônia. E-mail: regisbspaz@gmail.com. 
years old all schooled up until elementary school). Results indicate the existence of diaethnic influences on the lexical variation registered from the lexical Dragonfly item mapping.

KEYWORDS: ALEVA. Geosociolinguistic. Multidimensional and Relational Dialectology.

\section{Introdução}

O campo dos estudos dialetológicos e geolinguísticos tem crescido no Brasil desde a criação do Comitê Nacional para a elaboração do Atlas Linguístico do Brasil, em 1996. Desde a publicação do primeiro atlas linguístico brasileiro (Atlas Prévio dos Falares Baianos - APFB), em 1963, até 1996, haviam sido publicados no Brasil 5 atlas linguísticos regionais. Entre 1996 e 2010 foram elaborados e/ou publicados cerca de 16 atlas linguísticos que mapearam algum espaço do território brasileiro, como demonstrei em Guedes (2012, p. 51).

Na região norte, também em 1996, foi criado o primeiro projeto de um atlas linguístico estadual para a região, o projeto Atlas Geossociolinguístico do Pará ALiPA, sob a coordenação do prof. Abdelhak Razky, na UFPA. Atualmente, tem-se publicado, no estado, o ALiSPA (Atlas Linguístico Sonoro do Pará) além de outros projetos de atlas em andamento: ALeSPA (Atlas Léxico Sonoro do Pará), ALiPAI (Atlas Linguístico do Português em Áreas Indígenas), AGQUINPA (Atlas Geossociolinguístico Quilombola do Nordeste do Pará), e, mais recentemente, o ALEVA (Atlas Linguístico-Etnográfico do Vale do Acará), cujos dados são objeto deste estudo.

O projeto Atlas Linguístico-Etnográfico do Vale do Acará - ALEVA pode ser compreendido como a proposta de criação de um atlas linguístico de pequeno domínio, que objetiva a descrição das variedades do português falado na região do Vale do Rio Acará, localizada na Mesorregião Nordeste do Estado do Pará, que compreende variedades de contato com a língua japonesa (falada na comunidade de imigrantes presente no município), de contato com a língua Tembé (falada na terra indígena TuréMariquita), além das variedades do português quilombola (faladas em duas das comunidades de remanescentes de quilombos presentes no município).

As variáveis geossociolinguísticas estudadas neste projeto são as seguintes: diatópica (geográfica), diassexual (referente ao sexo dos colaboradores), diageracional 
(referente à idade dos colaborares) e diaétnica (que faz referência à etnia dos colaboradores). Em nossa perspectiva, a variável diaétnica consiste nas influências do fator etnicidade do colaborador na variação linguística. A pertença de um indivíduo a um determinado grupo étnico induz o mesmo a atitudes linguísticas comuns a esse grupo, à uma prática linguística que é ao mesmo tempo identitária.

O vale do rio Acará representa uma área de confluência linguística e cultural. A chegada de etnias diferentes ao território em momentos históricos distintos promoveu situações de contato linguístico diverso. O que faz dessa região, um campo profícuo para o estudo das influências da variável diaétnica no português falado na região.

Entre esses grupos que migraram para a região estão os indígenas da etnia Tembé, que constituem um subgrupo dos Tenetehára, vindos do Maranhão em meados do século XIX (NIMUENDAJÚ, 1948), estabelecendo-se nas bacias dos rios Guamá, Gurupi e Acará. Também no século XIX, estabeleceram-se na região descendentes de escravos formam hoje várias comunidades quilombolas, reconhecidas como tais, na região. Duas delas constituem pontos de inquérito do projeto ALEVA: Forte do Castelo e Itabocal Ponte.

Na primeira metade do século $\mathrm{XX}$, o governo brasileiro mantinha a política de incentivo à vinda de imigrantes estrangeiros para o país. Em 1929 desembarcava no Pará a primeira leva de imigrantes japoneses com a finalidade de desenvolver o setor da produção agrícola da região. A região do Vale do Rio Acará recebeu grande contingente de imigrantes japoneses desde então, e hoje essa é a terceira maior colônia japonesa do Brasil. Além disso, a região é entrecortada por rios, afluentes do Rio Acará, o que propiciou o estabelecimento de caboclos, que formam diversas comunidades ribeirinhas na região.

Esse encontro de línguas e culturas proporcionou à essa região uma diversidade linguístico-cultural significativa, que carece de estudos de natureza linguística, que possam dar conta da descrição dos processos linguísticos dela decorrentes. A região é caracterizada, portanto, por um plurilinguísmo motivado por esses processos migratórios.

O projeto do Atlas Linguístico-Etnográfico do Vale do Acará vem ao encontro dessa necessidade de descrição e estudo das variedades de fala que caracterizam a região. Para tanto, objetiva-se com esse projeto, descrever e mapear a variação 
linguística da região do Vale do Acará, com atenção especial ao português em contato com as línguas Tembé e Japonesa, bem como à variedade quilombola. Pretende-se, portanto, mapear a variação linguística nos níveis dialingual, diatópico, diageracional, diassexual, diastrático, diarreferencial e diaétnico. Dessa forma, a produção das cartas linguísticas do ALEVA deve demonstrar a variação linguística numa perspectiva pluridimensional.

\title{
1. O método geolinguístico: tendências contemporâneas
}

O fazer dos estudos dialetológicos remete ao século XIX, a partir de estudos feitos na Europa, como o Atlas Ethnographique du Globe (BALBI, 1826) Atlas Linguistique de l'Europe (BIONDELLI, 1841), passando pela elaboração dos trabalhos pioneiros de Wenker, no levantamento de dados para a elaboração do Atlas Linguístico da Alemanha Setentrional e Central (1881) e de Gilliéron e Edmont (1902-1910), na recolha sistemática de dados e publicação do Atlas Linguístico da França (ALF).

No dizer da saudosa professora Suzana Cardoso,

\begin{abstract}
Os estudos dialetológicos propriamente ditos vêm se iniciar num momento da história, século XIX, em que a individualidade geográfica de cada região estava resguardada pelo isolamento decorrente da frágil rede de estradas, seja pela dificuldade de comunicação, seja, ainda, pela inexistência de meios tecnológicos que permitissem a interação à distância entre as diferentes áreas, mas resultaram, principalmente da preocupação com o resgate de dados e a documentação dos diferentes estágios da língua. (CARDOSO, 2010, p. 39).
\end{abstract}

Na segunda metade do século XX, surgem os estudos da moderna dialetologia, influenciados pelo fazer da sociolinguística iniciada por Labov, na consideração das influências das variáveis sociais na variação e mudança linguísticas.

Nas últimas décadas do século $\mathrm{XX}$, vimos então o surgimento da Geossociolinguística (RAZKY, 1998) e da Dialetologia Pluridimensional e Relacional (RADKE; THUN, 1996). Perspectivas teórico-metodológicas que preveem o registro da pluridimensionalidade da variação nos atlas linguísticos. 
Observando-se o estado da arte da produção de atlas linguísticos do Brasil até o momento, vários pesquisadores ${ }^{1}$ procuraram classificá-los a partir de seus aspetos metodológicos: quanto ao espaço geográfico: atlas de pequenos, médios e grandes domínios; atlas estaduais, regionais e nacionais; quanto à natureza de seus dados: atlas de primeira, segunda e terceira geração; e quanto às variáveis linguísticas controladas: atlas monodimensionais, bidimensionais e pluridimensionais.

A partir de nossas reflexões e análises acerca das metodologias empregadas nesse conjunto de produtos geolinguísticos, embora sem termos feito uma explanação exaustiva sobre o tema, concluímos que há outras possibilidades de classificação a serem feitas sobre ele, a depender dos aspectos metodológicos considerados. Por exemplo, levadas em consideração as técnicas cartográficas que, historicamente, foram utilizadas na produção dos atlas linguísticos, deparamo-nos com os relatos dos autores dos primeiros atlas brasileiros, elaborados parcial ou integralmente de forma artesanal, por meio de escrita, desenhos, recortes e colagens, como testemunhamos em 2015, por ocasião dos relatos de experiências nas comemorações dos 50 anos do pioneiro Atlas Prévio dos Falares Baianos (APFB), durante o $11^{\circ}$ Workshop do Atlas Linguístico do Brasil (Do APFB ao ALiB: 50 anos de Geolinguística no Brasil), realizado na cidade de Salvador/BA.

Decorridos esses anos, com o acesso dos pesquisadores brasileiros a variados recursos computacionais e multimidiáticos, observamos a incorporação desses recursos na produção de atlas linguísticos. Hoje, são utilizados na produção dos atlas diversos softwares específicos da área de georreferenciamento, como ArcGIS e QGIS, além de softwares editores de imagens, como CorelDraw e Photoshop, Paint e Power Point. Por outro lado, foram desenvolvidos recentemente os primeiros softwares, produzidos com a participação de linguistas, para a geração automatizada de cartas linguísticas, como o Programa de Mapeamento Geolinguístico Digital - GeoLing (em desenvolvimento) e o Software para Geração e Visualização de Cartas Linguísticas JGVCLin (ROMANO; SEABRA; OLIVEIRA, 2014).

O GeoLing consiste em uma proposta de software que visa auxiliar o linguista que trabalha com o mapeamento de dados linguísticos em uma perspectiva geossociolinguística, gerando atlas linguísticos que poderão ser salvos em CD-ROM. O

\footnotetext{
${ }^{1}$ Cardoso (1999), Aguilera (2006), Lima (2006), Altino (2007), Cristianini (2007), Pereira (2007),
} Encarnação (2010), Sousa (2011), Guedes (2012), Isquerdo (2013), Romano (2013) e Reis (2013). 
programa possibilitará a entrada e a organização de dados fonéticos e lexicais, bem como de seus respectivos dados sonoros, em um mapa geográfico definido pelo pesquisador. Por meio do GeoLing, o pesquisador poderá otimizar o trabalho de organização de dados linguísticos e digitais, haja vista que a sua interface computacional foi pensada no sentido de ser interativa e de fácil manuseio. (RAZKY, 2008). Como o GeoLing vem sendo desenvolvido com os dados do ALeSPA, cujo tratamento de dados demandou tempo por conta dos processo de digitalização e trancrição, o GeoLing encontra-se em desenvolvimento no âmbito do projeto Geolinguística e Socioterminologia (GeoLinTerm).

O JGVCLin é uma ferramenta computacional que foi desenvolvida no âmbito de um projeto de doutorado em Estudos da Linguagem e que tem por objetivo "facilitar o processo de consulta ao material linguístico transcrito e armazenado em um banco de dados geral que servirá para quaisquer tipos de projetos" (ROMANO; SEABRA; OLIVEIRA, 2014, p. 126), possibilitando "a elaboração de cartas linguísticas e relatórios diversos de modo que o linguista realize o seu trabalho independentemente da intervenção de profissionais com formação em tecnologia da informação e outras áreas" (ROMANO; SEABRA; OLIVEIRA, 2014, p. 119). Os tutoriais e outras informações sobre o JGVCLin encontram-se disponíveis no site oficial do programa: $<$ http://sgvclin.altervista.org/>.

No contexto de desenvolvimento de softwares dessa natureza e de técnicas de cartografia geolinguística, em primeira instância, vimos a inclusão da policromia na produção dos atlas linguísticos. Tradicionalmente, como no pioneiro Atlas Linguístico da França (ALF), utilizava-se apenas a cor preta nos registros cartográficos, escolha que normalmente estava condicionada aos recursos disponíveis para impressão do atlas. Nesse caso, a identificação dos símbolos e legendas é a forma e não as cores. Sobre esse aspecto metodológico, é possível se fazer uma classificação do conjunto de atlas linguísticos produzidos quanto aos recursos cromáticos utilizados, em atlas monocromáticos e policromáticos.

É possível ainda, levando-se em consideração o suporte material utilizado, classificar os atlas como impressos ou digitais. Os suportes utilizados na cartografia comungam da mesma história dos utilizados na escrita em geral. Na gênese da cartografia, na produção dos primeiros mapas, foram utilizados como suporte de escrita 
o papiro, o pergaminho e o papel. Em se tratando da cartografia linguística, esta surgiu na "era do papel", e esse é, até os dias de hoje, o principal suporte material utilizado na publicação dos atlas linguísticos. Contudo, há também os atlas linguísticos nos quais foram adotados recursos computacionais como suportes de publicação. No Brasil, surgiram os primeiros atlas digitais em 2004. Nesse ano foi publicado o Atlas Linguístico Sonoro do Pará (ALiSPA), primeiro atlas brasileiro integralmente digital, que utiliza como suporte o CD-ROM. Formato que permitiu outras inovações, como a disponibilização do som da fala dos informantes (atlas parlants), acessado a partir de uma interface interativa, via computador. Além desse, registramos o Atlas Linguístico do Amazonas (ALAM), ainda não publicado, que possui apresentação impressa, visto que foi elaborado como tese de doutoramento em 2004, mas apresenta também uma interface digital, que, segundo Cruz-Cardoso (2016), no momento, está em fase de atualização, em vista de sua publicação. Além desses, tem-se hoje o projeto do Atlas Linguístico Sonoro das Línguas Indígenas do Brasil (ASLIB), cuja metodologia prevê, segundo Cabral e Razky (2014), a apresentação de uma plataforma interativa on line, que disponibilizará os dados sonoros, escritos e imagéticos do atlas.

Além dessas formas de classificação possíveis, propusemos uma classificação dos atlas linguísticos a partir da abordagem da Geolinguística Pluridimensional e Contatual (THUN, 1998), que preconiza a feitura de atlas que mapeiam situações de contato linguístico. Essa nova classificação propõe a divisão desses estudos, como atlas monolinguais e dialinguais.

\section{Pesquisa de campo}

A pesquisa de campo na área dos estudos dialetológicos está baseada, desde a sua gênese, no tripé rede pontos-informantes-questionários. Como assinalamos:

\footnotetext{
Na dimensão geossociolinguística, em se tratando da rede de pontos e do uso de questionários, observa-se uma continuidade dessas práticas; todavia, têm sido feitas algumas adaptações metodológicas, especialmente na diversificação e aplicação dos questionários. Por outro lado, no que se refere ao perfil do informante da pesquisa, a abordagem dos estudos geossociolinguísticos previu uma ampliação do campo de observação desse constituinte metodológico (RAZKY; GUEDES; COSTA, 2018, p. 128).
} 
Dessa forma, vimos tanto uma abrangência maior com relação à seleção dos colaboradores, que, nos primeiros atlas, eram um ou dois por ponto de inquérito, e que nos estudos da moderna dialetologia passam a ser quatro, seis, oito ou dez, com a inclusão do mapeamento de variáveis sociais, como sexo e idade dos colaboradores. No projeto ALEVA, o número de colaboradores é igual a seis, com o controle de três faixas etárias e de ambos os sexos, como veremos adiante.

\subsection{Rede de pontos de inquérito}

A rede de pontos de inquérito do ALEVA está em construção. Até o presente momento ela é composta pelos pontos de inquérito dispostos no quadro 1:

Quadro 1: Rede de Pontos de Inquérito

\begin{tabular}{lll}
\hline & PONTOS & NATUREZA DO PONTO \\
\hline $\mathbf{1}$ & TOMÉ-ACÚ & Comunidade Nipônica \\
$\mathbf{2}$ & QUATRO BOCAS & Comunidade Nipônica \\
$\mathbf{3}$ & ALDEIA TEKNAY & Comunidade Indígena \\
$\mathbf{4}$ & ALDEIA KUNAWARU & Comunidade Indígena \\
$\mathbf{5}$ & ITABOCAL PONTE & Comunidade Quilombola \\
$\mathbf{6}$ & FORTE DO CASTELO & Comunidade Quilombola \\
\hline
\end{tabular}

Fonte: Elaborado pelo autor

Foram levados em consideração no processo de eleição dos pontos de inquérito os seguintes fatores: (i) localização da comunidade na região do Vale do Acará; (ii) representatividade histórica e social das comunidades; e (iii) quantidade de habitantes por localidade. Foram selecionados inicialmente seis pontos de inquérito, representativos das etnias/comunidades tradicionais que compõem a diversidade étnicocultural do vale do Acará, sendo dois pontos para a comunidade nipônica, dois para a comunidade indígena e dois para a comunidade quilombola. Todavia, essa lista dos pontos de inquérito ainda pode ser ampliada em vista da existência de ribeirinhos e da comunidade de descendentes japoneses do município do Acará. 
$\mathrm{O}$ acesso aos pontos de inquérito afastados da zona urbana constitui por si um desafio, em função das distâncias, transportes, estradas e custos. Todavia, a pesquisa de campo do projeto ALEVA segue, mesmo que ainda não se tenha o apoio de agências de fomento de pesquisa.

\subsection{Perfil dos colaboradores}

A nomenclatura "informante" ainda é utilizada tradicionalmente no âmbito dos estudos dialetológicos para definir os indivíduos que constituem a fonte da informação. Contudo, optamos por utilizar a nomenclatura "colaborador" para definir esse elemento da pesquisa.

O projeto ALEVA tem o objetivo de descrever e mapear a variação linguística da região do Vale do Acará, com atenção especial ao português em contato com as línguas Tembé e Japonesa, bem como à variedade quilombola. Prevê o mapeamento do português falado por moradores dessa região, que é composta por um mosaico étnico variado, do qual fazem parte comunidades tradicionais como indígenas, quilombolas e ribeirinhos, e descendentes da comunidade de imigração japonesa.

Em cada ponto de inquérito o projeto prevê a entrevista de seis colaboradores, cujo perfil está descrito no quadro 2:

Quadro 2: Perfil dos colaboradores

\begin{tabular}{|c|c|c|}
\hline & COLABORADORES & ESCOLARIDADE \\
\hline 1 & 1 Menino, 10-12 anos & Matriculado na escola \\
\hline 2 & 1 Menina, 10-12 anos & Matriculado na escola \\
\hline 3 & 1 Homem, 18-30 anos & não escolarizado ou escolarizado até a $8^{\mathrm{a}}$ série $\left(9^{\circ}\right.$ ano) \\
\hline 4 & 1 Mulher, 18-30 anos & não escolarizada ou escolarizada até a $8^{\mathrm{a}}$ série $\left(9^{\circ}\right.$ ano $)$ \\
\hline 5 & 1 Homem, 50-75 anos & não escolarizado ou escolarizado até a $8^{\mathrm{a}}$ série $\left(9^{\circ}\right.$ ano) \\
\hline 6 & 1 Mulher, 50-75 anos & não escolarizada ou escolarizada até a $8^{\mathrm{a}}$ série $\left(9^{\circ}\right.$ ano $)$ \\
\hline
\end{tabular}

Fonte: Projeto ALEVA

\subsection{Questionários}


O mapeamento realizado pelo ALEVA tem o objetivo de descrever o falar da região do Vale do Acará a partir das variáveis diatópica, diassexual, diageracional, diarreferencial, dialingual e diaétnica.

Para tanto, os questionários aplicados para a elaboração do ALEVA são três: (i). Questionário Sociolinguístico (QS), que têm por finalidade identificar a situação sociolinguística da comunidade em relação ao grau de bilinguismo e aos comportamentos linguísticos dos falantes em relação às línguas faladas nas comunidades (Português, Tembé e Japonês); (ii). Questionário Fonético-Fonológico (QFF), que é orientado principalmente, mas não exclusivamente, no sentido de identificar as áreas em que ocorrem fatos fônicos já documentados para o português em pesquisas anteriores ou oriundos do contato linguístico; (iii). Questionário Semântico Lexical (QSL). O QFF e QSL utilizados foram elaborados pelo Comitê do Atlas Linguístico do Brasil - ALiB, com uma adaptação para capturar o bilinguismo dos colaboradores, no caso das comunidades japonesa e indígena. Essa adaptação se dá a partir da pergunta: "E na sua língua como se chama isso?". Indagação essa que é feita após cada uma das perguntas do QFF e do QSL no intuito de registrar o conhecimento lateral de outra língua além da portuguesa. A última questão do QSL utilizado requer do colaborador uma narrativa de um relato de experiência pessoal ou história da cultura tradicional na etnia investigada, que tem a finalidade de propiciar o estudo de um nível de fala mais espontâneo.

O Questionário Sociolinguístico (QS) aplicado visa captar a variação diarreferencial que ocorre nas comunidades, por meio do registro de comentários metalinguísticos e epilinguísticos. Como exemplo, temos a questão número 19: Como você $[o(a)$ senhor $(a)]$ avalia $o$ [Português/Tembé/Japonês] em termos de língua falada no lugar? a) legal b) grosseira c) bonita d) errada e) engraçada f) outros. Por quê?

Após a testagem dos questionários adaptados em comunidades indígenas pesquisadas em Guedes (2017), como a comunidade indígena Suruí-Aikewára, decidiuse por utilizar sempre que necessário (especialmente com as crianças e idosos) os questionários QFF e QSL ilustrados, por meio dos quais as perguntas indiretas são substituídas ou seguidas da apresentação de imagens impressas que representam o 
conceito requisitado em cada questão. Os questionários ilustrados também estão sendo utilizados nos inquéritos do ALEVA.

Na coleta de dados está sendo aplicado o método da pesquisa em três tempos, ou "passo triplo", desenvolvido por THUN (1997), que prevê três passos no momento de realização dos inquéritos: perguntar, insistir e sugerir. Por exemplo, quando da aplicação do QSL, na questão 88? Deve-se perguntar: " ... o inseto de corpo comprido e fino, com quatro asas bem transparentes, que voa e bate a parte traseira na água? Em caso de não resposta deve-se insistir reformulando a pergunta, por exemplo: "ele é bem pequeno, voa parece um aviãozinho e bate na água assim (fazendo o gesto com a mão)". Caso persista a falta de resposta deve-se sugerir: "você usa as palavras libélula, jacinta, lavadeira...?". Nessa técnica de recolha de dados é possível registrar o nível de domínio e uso de determinado item lexical.

As entrevistas, geralmente, estão sendo segmentadas em duas ou três partes, em função da postura, cansaço ou prontidão dos colaboradores, tendo em vista a extensão do tempo de aplicação dos questionários que juntos totalizam aproximadamente 836 perguntas.

\subsection{Cartografia dos dados}

Na elaboração das cartas linguísticas do ALEVA têm-se utilizado o software editor de imagens CorelDraw X8, que gera cartas digitais em alta resolução e coloridas. Seguimos o padrão de cores adotado no projeto ALiB. O mapa base que está sendo utilizado para a elaboração das cartas experimentais, como a que é apresentada neste estudo, foi elaborado por um técnico de georreferenciamento, a partir do software ArcGIS. Para a elaboração das cartas experimentais se escolheu o modelo de carta pluridimensional, que possibilita a leitura das variáveis consideradas na pesquisa simultaneamente: diatópica, diassexual, diageracional e diaétnica.

\section{Análise dos dados}

Analisando-se os dados cartografados na carta experimental 01 (figura 1), observamos que algumas escolhas lexicais dos colaboradores parecem demonstrar a pertença dos mesmos a uma determinada etnia, o que em nossa visão pode ser nomeado 
como variação diaétnica. $\mathrm{Na}$ carta experimental 01 , que foi elaborada a partir dos dados coletados sobre a questão 85 do QSL, cuja resposta esperada é "libélula". A lexia registrada em maior frequência foi "jacinta" com 56,25\% (18) das ocorrências, seguida por "libélula" com 34,37\% (11) das ocorrências. As lexias "macaco seco", "tombo" e "grilo" foram registradas no ponto de inquérito 1 (comunidade nipônica).

Figura 2: Carta Experimental 01 - ALEVA

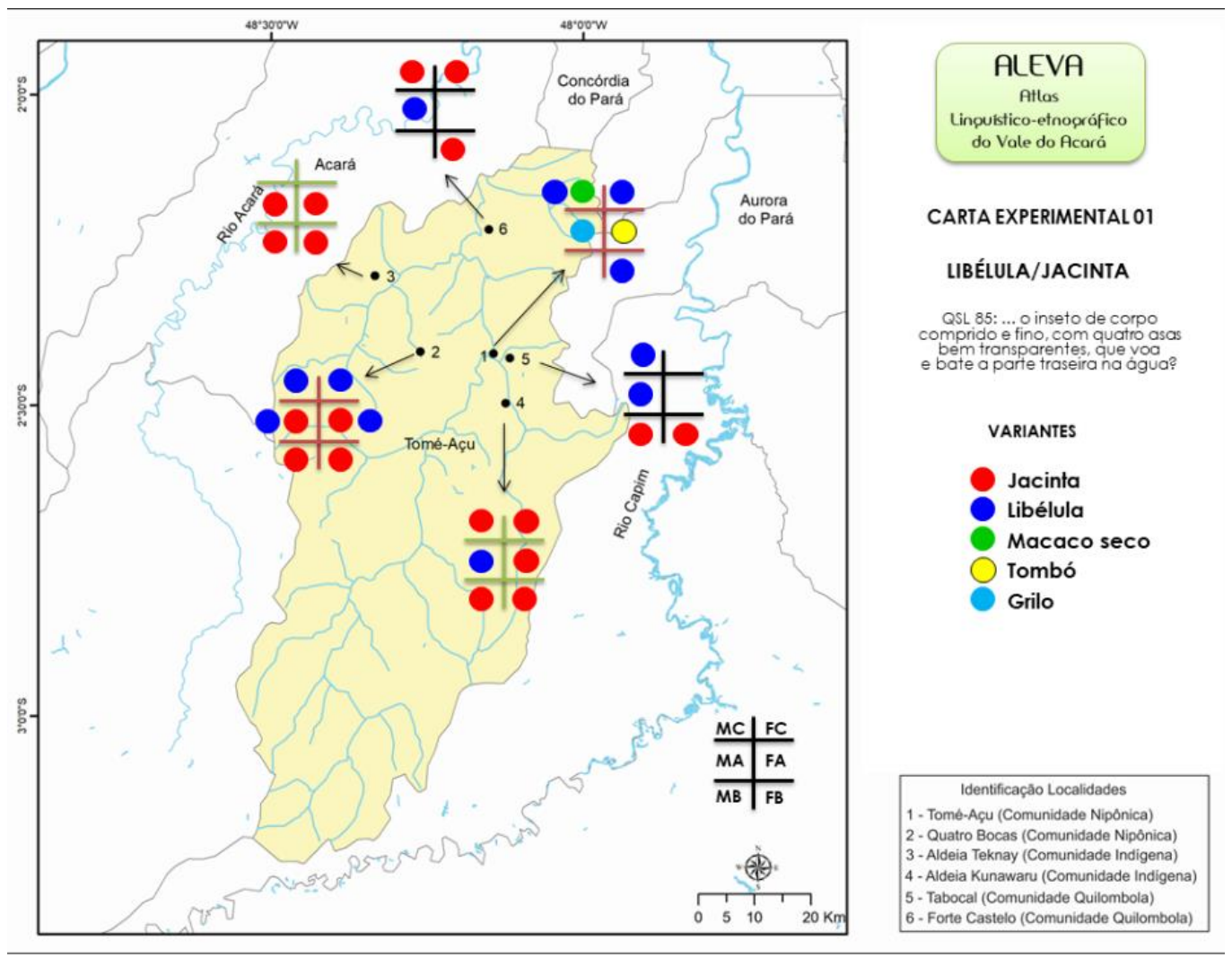

Fonte: Projeto ALEVA

O fator diaétnico emerge da análise quando se verifica que a lexia "jacinta" predomina nas comunidades indígenas (pontos 3 e 4). O dicionário Houaiss (2001) traz o verbete jacina, como de origem tupi, derivado de ya'sina, inseto de ordem dos odonatos, espécie de libélula, também conhecida como lavadeira. Isso pode justificar a predominância da lexia jacinta nas duas comunidades indígenas falantes de uma língua Tupí-Guaraní, o tembé.

Por outro lado, a lexia libélula predomina entre os colaboradores nipônicos (pontos 1 e 2). Ressaltamos também, na figura 2, o registro da lexia tombó, claramente 
um empréstimo da língua japonesa, que significa justamente libélula nesta língua. $\mathrm{O}$ registro foi feito na fala da colaboradora FA1, pertencente a comunidade nipônica de Tomé-açu sede (ponto 1). Entre os descendentes de japoneses (pontos 1 e 2) a lexia mais recorrente é libélula, que consideramos a variante inovadora, a partir dos percentuais de ocorrência diageracional.

Em referência à variável diageracional, os dados dão indícios de que a lexia jacinta é a variante mais conservadora, uma vez que predomina entre os colaboradores mais velhos, tendo alcançado percentuais de $90 \%$ na $3^{a}$ faixa etária (50 a 75 anos), $41 \%$ na segunda faixa (18 a 40 anos). Por outro lado, os dados dão indícios de que a lexia libélula é a variante inovadora, uma vez que está presente em maior frequência na fala dos colaboradores da $1^{\mathrm{a}}(62,5 \%)$ e $2^{\mathrm{a}}(41,6 \%)$ faixas etárias.

A cartografia dos dados no ponto de inquérito nipônico número 2 (Quatro Bocas), mostra que a lexia jacinta predomina entre os adultos mais velhos ( $3^{\mathrm{a}}$ faixa etária). Na segunda faixa etária, formada por adultos mais jovens, vemos a ocorrência em igual percentual de jacinta e libélula. Enquanto que na fala das crianças nipônicas desse ponto, o predomínio é da variante inovadora libélula. O que pode espelhar a realidade do contato linguístico, se considerarmos que os descendentes de japoneses da $3^{\text {a }}$ faixa etária aprenderam a língua portuguesa falando com os habitantes locais, como indígenas e caboclos, ao passo que a geração seguinte ( $2^{\mathrm{a}}$ faixa), teve maior acesso à escolarização, enquanto que entre as crianças nipônicas deste ponto de inquérito a variante conservadora jacinta não foi registrada.

Ao analisarmos os dados cartografados nas duas comunidades quilombolas, observa-se que, na comunidade Forte do Castelo (ponto 5), que é uma comunidade mais afastada do centro urbano, a variação deste item lexical apresenta predomiância da variante conservadora jacinta, inclusive entre as crianças e os idosos. O que demonstra a vitalidade desse uso. Por outro lado, na comunidade Itabocal-Ponte (ponto 6), que está localizada às margens da rodovia PA 451, que dá acesso aos centros urbanos da região, a variante predominante entre as crianças e adultos jovens é a inovadora libélula, persistindo o uso da variante conservadora jacinta na fala dos colaboradores mais velhos.

\section{Considerações finais}


A partir dessa explanação sobre os aspetos metodológicos adotados no projeto Atlas Linguístico-Etnográfico do Vale do Acará - ALEVA, consideramos que o delineamento metodológico traçado para a realização do projeto segue suprindo as necessidades oriundas das características próprias para a coleta de dados nas comunidades-alvo desta pesquisa.

As decisões metodológicas para o tratamento e cartografia dos dados coletados estão gerando os primeiros resultados no formato de cartas linguísticas experimentais que projetam a diversidade linguística do Vale do Acará de forma eficiente.

A coleta já foi finalizada nos seis pontos de inquérito previstos nesta primeira etapa: a comunidade japonesa nos pontos Tomé-Açu (sede) e Quatro Bocas, as duas aldeias indígenas Teknay e Kunawaru e as duas comunidades quilombolas Itabocal Ponte e Forte do Castelo.

A análise da carta experimental 01, sobre a questão 85 (item lexical "libélula") do QSL aplicado, permitiu verificar a variação lexical presente na região do Vale do Rio Acará, no nordeste do estado do Pará, especialmente se levada em conta a diversidade étnica da região. Da mesma forma, acreditamos que o mapeamento do corpus do projeto ALEVA demonstrará com mais clareza as influências da variável diaétnica na variação geolinguística do português falado nessa região, sendo, por tanto, necessária a continuidade do mapeamento desse corpus.

\section{REFERÊNCIAS}

AGUILERA, Vanderci de Andrade.. A geolingüística no Brasil: estágio atual. Revista da ABRANLIN, v. 5, n. 1/2, p. 215-238, dez. 2006. Disponível em: <http://www.abralin.org/revista/RV5N1_2/RV5N1_2_art10.pdf>. Acesso em: 01 set. 2018.

ALTINO, Fabiane Cristina. Atlas linguístico do Paraná II. 2007.693 p. Tese (Doutorado em Estudos da Linguagem) - Centro de Letras e Ciências Humanas da Universidade Estadual de Londrina, Londrina, 2007. 
CABRAL, A. S. A. C.; RAZKY, A. Projeto atlas linguístico sonoro das línguas indígenas do Brasil. 2014 (Projeto de Pesquisa/CNPQ) Não publicado

CARDOSO, Suzana Alice. Geolinguística: tradição e modernidade. São Paulo: parábola, 2010.

CARDOSO, Suzana Alice Marcelino. A Dialectologia no Brasil: perspectivas. Delta. vol. 15, n. ${ }^{\circ}$ especial, 1999. p.233-255.

CRISTIANINI, Adriana C. Atlas semântico lexical da região do grande ABC. 2007. 635 p. Tese (Doutorado em Linguística) - Faculdade de Filosofia, Letras e Ciências Humanas da Universidade de São Paulo, São Paulo, 2007.

CRUZ-CARDOSO, M. L. de C. O atlas linguístico do Amazonas - ALAM. In: AGUILERA, V. de A.; ROMANO, V. P. (org.). A geolinguística no Brasil: caminhos percorridos, horizontes alcançados. Londrina: Eduel, 2016

ENCARNAÇÃO, Marcia. R. T. da. Atlas semântico-lexical de Caraguatatuba, Ilhabela, São Sebastião e Ubatuba: municípios do litoral norte de São Paulo. 2010. 723 p. Tese (Doutorado em Linguística) - Faculdade de Filosofia, Letras e Ciências Humanas da Universidade de São Paulo, São Paulo, 2010.

GUEDES, Regis José da Cunha Guedes. Perfil geossociolinguístico do português em contato com línguas tupí-guaraní em áreas indígenas dos estados do Pará e Maranhão. 2017. Tese (Doutorado em Letras) - Universidade Federal do Pará, Belém, 2017.

ISQUERDO, Aparecida Negri.. Atlas regionais em andamento no Brasil: perspectivas metodológicas. In: AGUILERA, Vanderci de Andrade. A geolingüística no Brasil: trilhas seguidas, caminhos a percorrer. Londrina: Eduel, 2013. p. 333-356 
LIMA, Luciana Gomes de. Atlas fonético do entorno da baía da Guanabara AFeBG. 2006. 158 p. Dissertação (Mestrado em Estudos da Linguagem) Departamento de Letras Vernáculas, Universidade Federal do Rio de Janeiro, Rio de Janeiro, 2006.

NIMUENDAJÚ, Curt. Tribes of the lower and middle Xingú river. Handbook of South American Indians 3. p. 213-243. Washington, 1948.

PEREIRA, Maria das Neves. Atlas Geolinguístico do Litoral Potiguar. 2007. 312 p. Tese (Doutorado em Língua Portuguesa) - Faculdade de Letras da Universidade Federal do Rio de Janeiro, Rio de Janeiro, 2007.

RADTKE, Edgar; THUN, Harald. Neue Wege der romanischen Geolinguistik: Eine Bilanz. In: RADTKE; Edgar; THUN, Harald (eds.). Neue Wege der romanischen Geolinguistik: Akten des Symposiums zur empirischen Dialektologie. Kiel: WestenseeVerl., 1996. p. 1-24.

RADTKE, Edgar; THUN, Harald. Dialectologia pluridimensionalis romanica. Kiel: Westensee-Verlag, 1996.

RAZKY, Abdelhak. O Atlas geo-sociolinguístico do Pará: Abordagem metodológica. In: AGUILERA (Org). A geolingüística no Brasil: caminhos e perspectivas. Londrina: UEL, 1998.

RAZKY, Abdelhak. Atlas linguístico sonoro do estado do Pará (ALiSPA 1.1). Belém: s/ed. 2004. (Programa em CD-ROM).

RAZKY, A. Programa de Mapeamento Geolinguístico Digital. In: Encontro CELSUL Círculo de Estudos Linguísticos do Sul, 8., 2008, Porto Alegre. Programação e Resumos [...]. Pelotas: EDUCAT, 2008. p. 390. 
RAZKY, Abdelhak; GUEDES, Regis J. da C.; COSTA, Eliane O. da. A pesquisa geolinguística em áreas indígenas brasileiras: desafios e estratégias. Signum: estudos da linguagem, Londrina, v. 21, n.1, p. 126-138, adr. 2018.

REIS, Regiane Coelho Pereira. Atlas linguístico do município de Ponta Porã ALiPP. 2006. Dissertação (Mestrado em Letras) - Universidade Federal de Mato Grosso do Sul, Campo Grande, 2006.

REIS, Regiane Coelho Pereira. Variação linguística do português em contato com o espanhol e o guarani na perspectiva do atlas linguístico-contatual da fronteira da fronteira entre Brasil e Paraguai (ALF-BR PY). Tese (Doutorado em Estudos da Linguagem) - Universidade Estadual de Londrina, Londrina, 2013.

RODRIGUES, Aryon Dall'Igna. Os cenários da chegada da língua portuguesa. In: CARDOSO, Suzana A.; MOTA, Jacyra A.; MATTOS E SILVA, Rosa V. Quinhentos anos de história linguística do Brasil. Salvador: Secretaria da Cultura e Tursimo do Estado do Bahia, 2006.

ROMANO, V. Balanço crítico da Geolinguística brasileira e a proposição de uma divisão. Entretextos. Londrina, v.13, nº 02, p. 203-242, jul./dez. 2013.

ROMANO, V. P.; SEABRA, R. D.; OLIVEIRA, N. [JGVCLin] - software para geração e visualização de cartas linguísticas. Revista Estudos da Linguagem, Belo Horizonte, v. 22 , n. 1 , p. $119-151$, jan./jun. 2014

SOUSA, Gracione Teixeira de. Atlas linguístico do Acre: cartas fonéticas da região do Purus. 2011. 170. Dissertação (Mestrado em Letras) - Departamento de Letras, Universidade Federal do Acre, Acre, 2011.

THUN, Harald. La geolingüística como lingüística variacional general (con ejemplos del Atlas linguístico Diatópico y Diastrático del Uruguay). In: RUFFENO, Giovanni. 
International Congress of Romance Linguístics an Philology. Tübingen: Niemeyer, 1998. 